Антибиотикорезистентность, продукция карбапенемаз и генотипы нозокомиальных штаммов Acinetobacter spp. в стационарах России: результаты многоцентрового эпидемиологического исследования «МАРАФОН 2015-2016»

Шек Е.А. ${ }^{1}$, Сухорукова М.В. ${ }^{1}$, Эйдельштейн М.В. ${ }^{1}$, Склеенова Е.Ю. ${ }^{1}$, Иванчик Н.В. ${ }^{1}$, Шайдуллина Э.Р. ${ }^{1,2}$, Кузьменков А.Ю. ${ }^{1}$, Дехнич А.В. ${ }^{1}$, Козлов Р.С. ${ }^{1}$, Семенова Н.В. ${ }^{3}$, Слепакова С.А. ${ }^{4}$, Шепотайлова Н.В. ${ }^{4}$, Стребкова В.В. ${ }^{5}$, Рыбина Н.А. ${ }^{5}$, Яранцева Н.3. ${ }^{6}$, Перевалова Е.Ю. ${ }^{7}$, Розанова С.М. ${ }^{7}$, Наговицина С.Г. ${ }^{8}$, Молдовану М.Г. ${ }^{8}$, Насыбуллова 3.3. ${ }^{9}$, Архипенко М.В. ${ }^{10}$, Шахмурадян Р.М. ${ }^{10}$, Нижегородцева И.А. ${ }^{11}$, Варибрус Е.В. ${ }^{11}$, Александрова И.А. ${ }^{12}$, Лазарева А.В. ${ }^{13}$, Крыжановская О.А. ${ }^{13}$, Маркелова Н.Н. ${ }^{14}$, Чернявская Ю.Л. ${ }^{15}$, Лебедева Е.В. ${ }^{15}$, Кириллова Г.Ш. ${ }^{16}$, Беккер Г.Г. ${ }^{17}$, Попова Л.Д. ${ }^{18}$, Елохина Е.В. ${ }^{18}$ Смолькова Ю.Е. ${ }^{19}$, Зиновьев Д.Ю. ${ }^{19}$, Итяева Л.Н. ${ }^{20}$, Блинова Г.Ю. ${ }^{20}$, Зубарева Н.А. ${ }^{21}$, Витязева В.П. ${ }^{22}$, Плаксина М.Г. ${ }^{22}$, Куцевалова О.Ю. ${ }^{23}$, Панова Н.И. ${ }^{23}$, Суборова Т.Н. ${ }^{24}$, Полухина О.В. ${ }^{25}$, Ворошилова Т.М. ${ }^{26}$, Чурикова Е.М. ${ }^{26}$, Москвитина Е.Н. ${ }^{27}$, Кречикова О.И. ${ }^{1}$, Петрова Т.А. ${ }^{28}$, Мартьянова Н.М. ${ }^{29}$, Хохлова К.О. ${ }^{29}$, Гудкова Л.В. ${ }^{30}$, Быконя С.А. ${ }^{30}$, Хохлявина Р.М. ${ }^{31}$, Шпилькина Л.В. ${ }^{31}$, Бурасова Е.Г. ${ }^{32}$, Хребтовская В.А. ${ }^{32}$, Молчанова И.В. ${ }^{33}$, Звонарева О.В. ${ }^{33}$, Корнилова П.А. ${ }^{34}$, Крянга В.Г. ${ }^{34}$, Портнягина У.С. ${ }^{35}$, Шамаева С.Х. ${ }^{35}$

1 НИИ антимикробной химиотерапии ФГБОУ ВО СГМУ Минздрава России, Смоленск, Россия

2 ФГАОУ ВО «Казанский (Приволжский) федеральный университет», Казань, Россия

${ }^{3}$ Архангельская областная клиническая больница, Архангельск, Россия

${ }^{4}$ Амурская областная детская клиническая больница, Благовещенск, Россия

5 Воронежская городская клиническая больница скорой медицинской помощи №10, Воронеж, Россия

${ }^{6}$ Свердловская областная клиническая психиатрическая больница, Екатеринбург, Россия

7 Клинико-диагностический центр, Екатеринбург, Россия

8 Городская клиническая больница №9, Ижевск, Россия

9 Республиканская клиническая больница, Казань, Россия

10 Научно-исследовательский институт - Краевая клиническая больница №1 им. проф. С.В. Очаповского, Краснодар, Россия

11 Краевая клиническая больница №2, Краснодар, Россия

12 ФГАУ «НМИЦ нейрохирургии им. акад. Н.Н. Бурденко» Минздрава России, Москва, Россия

13 ФГАУ «НМИЦ здоровья детей» Минздрава России, Москва, Россия

14 ФГБУ «Российский научный центр рентгенорадиологии» Минздрава России, Москва, Россия

${ }^{15}$ Мурманская областная клиническая больница им. П.А. Баяндина, Мурманск, Россия

${ }^{16}$ Больница скорой медицинской помощи, Набережные Челны, Россия

17 Дорожная клиническая больница на ст. Новосибирск-Главный ОАО «РЖД», Новосибирск, Россия

18 Областная клиническая больница, Омск, Россия

19 Клиническая больница №6 им. Г.А. Захарьина, Пенза, Россия

20 Областной онкологический диспансер, Пенза, Россия

21 ФГБОУ ВО «Пермский государственный медицинский университет им. акад. Е.А. Вагнера» Минздрава России, Пермь, Россия

22 Детская республиканская больница, Петрозаводск, Россия

23 ФГБУ «Ростовский научно-исследовательский онкологический институт» Минздрава России, Ростов-на-Дону, Россия

24 ФГБВОУ ВО «Военно-медицинская академия им. С.М. Кирова» Минобороны России, Санкт-Петербург, Россия

${ }^{25}$ Санкт-Петербург, Россия

${ }^{26}$ ФГБУ «Всероссийский центр экстренной и радиационной медицины им. А.М. Никифорова» МЧС России, Санкт-Петербург, Россия

27 ФГБУ «Сибирский федеральный научно-клинический центр» ФМБА России, Северск, Россия

28 Клиническая больница №1, Смоленск, Россия

29 Тольяттинская городская клиническая больница №5, Тольятти, Россия

30 Томская областная клиническая больница, Томск, Россия

31 Областная клиническая больница №1, Тюмень, Россия

32 Республиканская клиническая больница им. Н.А. Семашко, Улан-Удэ, Россия

33 Челябинская областная клиническая больница, Челябинск, Россия

34 Республиканская больница №1 - Национальный центр медицины, Якутск, Россия

35 Республиканская больница №2 - Центр экстренной медицинской помощи, Якутск, Россия

Контактный адрес:

Марина Витальевна Сухорукова Эл. почта: Marina.Sukhorukova@ antibiotic.ru

Ключевые слова: нозокомиальные инфекции, Acinetobacter spp., A. baumannii, антибиотикорезистентность, карбапенемазы.
Цель. Определить распространенность устойчивости к антибиотикам и продукции приобретенных карбапенемаз у нозокомиальных штаммов Acinetobacter spp., а также генотипы и принадлежность к «международным клонам высокого риска» штаммов Acinetobacter baumannii, выделенных в различных регионах России в рамках многоцентрового эпидемиологического исследования «МАРАФОН 2015-2016».

Материалы и методы. Всего исследовано 1005 неповторяющихся изолятов Acinetobacter spp., включая 975 изолятов A. baumannii, выделенных в 44 стационарах 25 городов России в 20152016 гг. Видовую идентификацию изолятов проводили методом MALDI-TOF масс-спектрометрии. 
Определение чувствительности к антибиотикам выполняли методом микроразведений в бульоне в соответствии со стандартом ISO 20776-1:2006, результаты интерпретировали на основании пограничных значений МПК, рекомендованных EUCAST, версия 9.0. Наличие генов приобретенных карбапенемаз групп OXA-23, OXA-24/40, OXA-58, VIM, IMP, NDM, GES-2 и GES-5 определяли с помощью ПЦР в реальном времени. Генотипирование A. baumannii проводили на основании идентификации однонуклеотидных полиморфизмов в 10 хромосомных локусах, используемых в существующих схемах мультилокусного секвенирования-типирования (MLST).

Результаты. Acinetobacter spp., и в частности A. baumannii, составили соответственно 17,4\% и 16,8\% от всех бактериальных возбудителей, выделенных в рамках исследования «МАРАФОН 2015-2016». Устойчивость к карбапенемам (имипенему и меропенему) проявляли соответственно $77,4 \%$ и 77,1\% изолятов A. baumannii. У $76,2 \%$ изолятов $A$. baumannii выявлено наличие генов приобретенных карбапенемаз молекулярного класса D, относящихся к группам OXA-24/40 $(57,5 \%)$, OХА-23 $(18,4 \%)$ и ОХА-58 $(0,1 \%)$; причем у двух изолятов $(0,2 \%)$ - одновременное наличие генов ОХА-24/40- и ОХА-23-подобных бета-лактамаз. Большинство продуцентов карбапенемаз относились к «международным клонам высокого риска»: CC92/2080ХF/CC2 2 PAs $(60,3 \%$ ), CC944 OXF/CC78 PAS $(25,4 \%)$ и CC109/231 OXF/CC1PAS $(11,6 \%)$. Подавляющее большинство изолятов A. baumannii были устойчивыми к ципрофлоксацину $(99,0 \%)$, амикацину $(89,2 \%)$ и гентамицину $(77,4 \%)$. Частота резистентности к тобрамицину и триметоприму/сульфаметоксазолу была различной у штаммов разных генотипов. Наиболее высокой активностью in vitro обладал колистин $10,9 \%$ резистентных изолятов). Штаммы других видов Acinetobacter spp. были более чувствительны к различным антибиотикам, однако у двух изолятов Acinetobacter ursingii и Acinetobacter baylyi были выявлены гены металло-бета-лактамаз группы NDM.

Выводы. Результаты проведенного исследования свидетельствуют о чрезвычайно высокой распространенности резистентности к большинству антибиотиков, включая карбапенемы, у нозокомиальных штаммов Acinetobacter spp. В связи с этим выбор антибиотиков для эмпирической терапии является крайне затруднительным и требует проведения регулярного локального мониторинга чувствительности в каждом стационаре.

Original Article

\section{Antimicrobial resistance, carbapenemase production, and genotypes of nosocomial Acinetobacter spp. isolates in Russia: results of multicenter epidemiological study "MARATHON 2015-2016"}

Shek E.A. ${ }^{1}$, Sukhorukova M.V. ${ }^{1}$, Edelstein M.V. ${ }^{1}$, Skleenova E.Yu. ${ }^{1}$, Ivanchik N.V. ${ }^{1}$, Shajdullina E.R. ${ }^{1,2}$, Kuzmenkov A.Yu. ${ }^{1}$, Dekhnich A.V. ${ }^{1}$, Kozlov R.S. ${ }^{1}$, Semyonova N.V. ${ }^{3}$, Slepakova S.A. ${ }^{4}$, Shepotajlova N.V. ${ }^{4}$, Strebkova V.V. ${ }^{5}$, Rybina N.A. ${ }^{5}$, Yaranceva N.Z. ${ }^{6}$, Perevalova E.Yu. ${ }^{7}$, Rozanova S.M. ${ }^{7}$, Nagovicina S.G. ${ }^{8}$, Moldovanu M.G. ${ }^{8}$, Nasybullova Z.Z. ${ }^{9}$, Arkhipenko M.V. ${ }^{10}$, Shakhmuradyan R.M. ${ }^{10}$, Nizhegorodceva I.A. ${ }^{11}$, Varibrus E.V. ${ }^{11}$, Aleksandrova I.A. ${ }^{12}$, Lazareva A.V. ${ }^{13}$, Kryzhanovskaya O.A. ${ }^{13}$, Markelova N.N. ${ }^{14}$, Chernyavskaya Yu.L. ${ }^{15}$, Lebedeva E.V. ${ }^{15}$, Kirillova G.Sh. ${ }^{16}$, Bekker G.G. ${ }^{17}$, Popova L.D. ${ }^{18}$, Elokhina E.V. ${ }^{18}$, Smol'kova Yu.E. ${ }^{19}$, Zinov'ev D.Yu. ${ }^{19}$, Ityaeva L.N. ${ }^{20}$, Blinova G.Yu. ${ }^{20}$, Zubareva N.A. ${ }^{21}$, Vityazeva V.P. ${ }^{22}$, Plaksina M.G. ${ }^{22}$, Kucevalova O.Yu. ${ }^{23}$, Panova N.I. ${ }^{23}$, Suborova T.N. ${ }^{24}$, Polukhina O.V. ${ }^{25}$, Voroshilova T.M. ${ }^{26}$, Churikova E.M. ${ }^{26}$, Moskvitina E.N. ${ }^{27}$, Krechikova O.I. ${ }^{1}$, Petrova T.A. ${ }^{28}$, Mart'yanova N.M. ${ }^{29}$, Khokhlova K.O. ${ }^{29}$, Gudkova L.V. ${ }^{30}$, Bykonya S.A. ${ }^{30}$, Khokhlyavina R.M. ${ }^{31}$, Shpil'kina L.V. ${ }^{31}$, Burasova E.G. ${ }^{32}$, Khrebtovskaya V.A. ${ }^{32}$, Molchanova I.V. ${ }^{33}$, Zvonaryova O.V. ${ }^{33}$, Kornilova P.A. ${ }^{34}$, Kryanga V.G. ${ }^{34}$, Portnyagina U.S. ${ }^{35}$, Shamaeva S.Kh. ${ }^{35}$

1 Institute of Antimicrobial Chemotherapy, Smolensk, Russia

2 Kazan Federal University, Kazan, Russia

${ }^{3}$ Arkhangelsk Regional Clinical Hospital, Arkhangelsk, Russia

${ }^{4}$ Amur Regional Children Clinical Hospital, Blagoveshchensk, Russia

${ }_{5}^{5}$ Voronezh City Clinical Emergency Care Hospital \#10, Voronezh, Russia

${ }^{6}$ Sverdlovsk Regional Clinical Psychiatric Hospital, Yekaterinburg, Russia

7 Clinical Diagnostic Center, Yekaterinburg, Russia

${ }^{8}$ City Clinical Hospital \#9, Izhevsk, Russia

${ }^{9}$ Republican Clinical Hospital, Kazan, Russia

${ }^{10}$ Research Institute - Regional Clinical Hospital \#1 named after Prof. S.V. Ochapovskij, Krasnodar, Russia

11 Regional Clinical Hospital \#2, Krasnodar, Russia

12 National Medical Research Center of Neurosurgery named after N.N. Burdenko, Moscow, Russia

${ }^{13}$ National Medical Research Center for Children's Health, Moscow, Russia

${ }^{14}$ Russian Scientific Center of Roentgenoradiology, Moscow, Russia

${ }^{15}$ Murmansk Regional Clinical Hospital named after P.A. Bayandin, Murmansk, Russia

${ }^{16}$ Emergency Care Hospital, Naberezhnye Chelny, Russia

${ }_{17}$ Clinical Hospital at the Novosibirsk-Main Station, Novosibirsk, Russia

${ }_{18}$ Regional Clinical Hospital, Omsk, Russia 
${ }^{19}$ Clinical Hospital \#6 named after G.A. Zakhar'in, Penza, Russia

20 Regional Oncology Dispensary, Penza, Russia

${ }^{21}$ Perm State Medical University named after E.A. Wagner, Perm, Russia

22 Children Republican Hospital, Petrozavodsk, Russia

${ }^{23}$ Rostov Research Institute of Oncology, Rostov-on-Don, Russia

${ }^{24}$ S.M. Kirov Military Medical Academy, Saint-Petersburg, Russia

${ }^{25}$ Saint-Petersburg, Russia

${ }^{26}$ All-Russian Center of Emergency and Radiation Medicine named after A.M. Nikiforov, Saint-Petersburg, Russia

${ }^{27}$ Siberian Federal Scientific Clinical Center, Seversk, Russia

${ }^{28}$ Clinical Hospital \#1, Smolensk, Russia

${ }^{29}$ Tol'yatti City Clinical Hospital \#5, Tol'yatti, Russia

30 Tomsk Regional Clinical Hospital, Tomsk, Russia

${ }^{31}$ Regional Clinical Hospital \#1, Tyumen, Russia

${ }^{32}$ Republican Clinical Hospital named after N.A. Semashko, Ulan-Ude, Russia

${ }^{33}$ Chelyabinsk Regional Clinical Hospital, Chelyabinsk, Russia

${ }^{34}$ Republican Hospital \#1 - National Medical Center, Yakutsk, Russia

${ }^{35}$ Republican Hospital \#2 - Center of Emergency Medical Care, Yakutsk, Russia

Contacts:

Marina V. Sukhorukova

E-mail: Marina.Sukhorukova@ antibiotic.ru

Key words: nosocomial infections, Acinetobacter spp., A. baumannii, antimicrobial resistance, carbapenemases.
Objectives. To assess the rates of antibiotic resistance and production of acquired carbapenemases in nosocomial strains of Acinetobacter spp., and to determine the genotypes and prevalence of "international high-risk clones" among nosocomial strains of Acinetobacter baumannii isolated in various regions of Russia within the "MARATHON 2015-2016" study.

Materials and methods. A total of 1005 non-duplicate nosocomial isolates of Acinetobacter spp., including 975 isolates of $A$. baumannii, collected in 44 hospitals from 25 cities in Russia in 20152016 were studied. Species identification of isolates was performed by means of MALDI-TOF massspectrometry. Antimicrobial susceptibility was determined using broth microdilution method according to ISO 20776-1:2006 and interpreted using EUCAST MIC clinical breakpoints v.9.0. The presence of acquired carbapenemase genes of OXA-23, OXA-24/40, OXA-58, VIM, IMP, NDM, GES-2 and GES-5 groups was determined using real-time PCR. Genotyping of $A$. baumannii isolates was performed by analysis of selected single nucleotide polymorphisms in 10 chromosomal loci used for multi-locus sequence tying (MLST) of this species.

Results. Acinetobacter spp. and A. baumannii comprised of $17.4 \%$ and $16.8 \%$ of all bacterial pathogens isolated within the "MARATHON 2015-2016" study. Resistance rates to carbapenems (imipenem and meropenem) were $77.4 \%$ and $77.1 \%$ of $A$. baumannii isolates, respectively. In $76.2 \%$ of $A$. baumannii isolates, the genes of acquired carbapenemases of molecular class $D$ were detected, which belonged to the following groups: OXA-24/40 (57.5\%), OXA-23 (18.4\%) and OXA-58 (0.1\%). Two isolates (0.2\%) carried the genes of OXA-24/40- и OXA-23-like carbapenemases simultaneously. Most carbapenemaseproducing isolates belonged to the «international high-risk clones»: CC92/2080XF/CC2 PAS $(60.3 \%)$, CC944 ${ }^{\mathrm{OXF}} / \mathrm{CC}^{\mathrm{PAS}}(25.4 \%)$ and CC109/231 $\mathrm{OXF} / \mathrm{CC}^{\mathrm{PAS}}(11.6 \%)$. The vast majority of $A$. baumannii isolates exhibited resistance to ciprofloxacin $(99.0 \%)$, amikacin $(89.2 \%)$ and gentamicin $(77.4 \%)$. The prevalence of resistance to tobramycin and trimethoprim/sulfamethoxazole was variable among strains of different genotypes. Colistin was the most active agent in vitro $(0.9 \%$ of resistant isolates). Isolates of other Acinetobacter species were more susceptible to most antibiotics. However, two isolates of Acinetobacter ursingii and Acinetobacter baylyi carried the genes of NDM metallo-beta-lactamases.

Conclusions. The results of this study indicate a very high prevalence of resistance to most antibiotics, including carbapenems, in nosocomial strains of Acinetobacter spp. This makes the selection of empiric antibiotic treatment extremely difficult and urges the need for regular local surveillance of resistance in every hospital.

\section{Введение}

В настоящее время Acinetobacter baumannii является одним из наиболее частых возбудителей нозокомиальных инфекций $[1,2]$. Родственные $A$. baumannii виды (A. nosocomialis, A. pittii, A. dijkshoorniae и $A$. seifertii) также обычно выделяются из образцов клинического материала госпитализированных пациентов, тогда как другие виды рода Acinetobacter, включая A. calcoaceticus, A. haemolyticus, $A$. junii, $A$. Iwoffii, $A$. ursingii и A. variabilis, - как правило, из объектов окружающей среды и лишь в редких случаях могут колонизировать или вызывать инфекции у госпитализированных пациентов [3-7]. Доля изолятов Acinetobacter spp. (n = 1005) среди всех бактериальных возбудителей нозокомиальных инфекций ( $n=5783)$, выделенных в рамках исследования «МАРАФОН» в 2015-2016 гг., составила 17,4\%. A. baumannii $(16,8 \%)$ был третьим по частоте встре- чаемости видом после Klebsiella pneumoniae $(22,8 \%)$ и Pseudomonas aeruginosa $(17,4 \%)$ (Таблица 1). Таким образом, A. baumannii на протяжении ряда лет остается одним из ведущих возбудителей нозокомиальных инфекций в России [8-13].

A. baumannii и родственные виды обладают значительно более низкой природной чувствительностью к большинству бета-лактамных антибиотиков, включая пенициллины и цефалоспорины, по сравнению с представителями порядка Enterobacterales. В связи с этим для лечения инфекций, вызванных данными возбудителями, обычно используются карбапенемы (кроме эртапенема) [1]. Однако в последнее время приобретенная резистентность к карбапенемам и антимикробным препаратам (АМП) других групп стремительно распространяется среди нозокомиальных штаммов Acinetobacter spp. 
Таблица 1. Видовой состав нозокомиальных изолятов Acinetobacter spp., выделенных в исследовании «MAРАФОН 2015-2016»

\begin{tabular}{l|c}
\hline \multicolumn{1}{c|}{ Вид } & Количество (\%) \\
\hline Acinetobacter baumannii & $975(97 \%)$ \\
\hline Acinetobacter pittii & $11(1,1 \%)$ \\
\hline Acinetobacter calcoaceticus & $5(0,5 \%)$ \\
\hline Acinetobacter nosocomialis & $3(0,3 \%)$ \\
\hline Acinetobacter guillouiae & $2(0,2 \%)$ \\
\hline Acinetobacter Iwoffii & $2(0,2 \%)$ \\
\hline Acinetobacter spp. ${ }^{*}$ & $2(0,2 \%)$ \\
\hline Acinetobacter ursingii & $2(0,2 \%)$ \\
\hline Acinetobacter baylyi & $1(0,1 \%)$ \\
\hline Acinetobacter junii & $1(0,1 \%)$ \\
\hline Acinetobacter seifertii & $1(0,1 \%)$ \\
\hline
\end{tabular}

* Изоляты, не относящиеся к A. baumannii, для которых не был получен однозначный результат видовой идентификации с помощью MALDI-TOF MS (Score 2,0-2,1).

во всем мире, что определяет необходимость проведения регулярного мониторинга чувствительности нозокомиальных штаммов Acinetobacter spp. и при необходимости коррекции стратегии терапии вызываемых ими инфекций $[1,14,15]$.

\section{Материалы и методы исследования}

Источники бактериальных изолятов. В исследование включали клинические изоляты рода Acinetobacter ( $\mathrm{n}=1005)$, собранные в рамках многоцентрового эпидемиологического исследования антибиотикорезистентности возбудителей нозокомиальных инфекций («МАРАФОН») в 44 стационарах 25 городов России (Архангельск, Благовещенск, Воронеж, Екатеринбург, Ижевск, Казань, Краснодар, Москва, Мурманск, Набережные Челны, Новосибирск, Омск, Пенза, Пермь, Петрозаводск, Ростов-на-Дону, Санкт-Петербург, Северск, Смоленск, Тольятти, Томск, Тюмень, Улан-Удэ, Челябинск и Якутск) с января 2015 г. по декабрь 2016 г. Выделение и первичная идентификация бактериальных изолятов проводились в локальных клинических микробиологических лабораториях центров-участников исследования. Все включенные в исследование изоляты были расценены как нозокомиальные с учетом: 1) их вероятной этиологической значимости в развитии определенной инфекции и 2) соответствия формальным критериям нозокомиальной инфекции - инфекции, развившейся у пациента не менее чем через 48 ч. после госпитализации, не находившейся в инкубационном периоде или явившейся следствием предшествующей госпитализации. Распределение исследованных изолятов в соответствии с источником их выделения и локализацией инфекции представлено на Рисунке 1. Окончательная видовая идентификация изолятов и определение их чувствительности к АМП проводились в центральной лаборатории

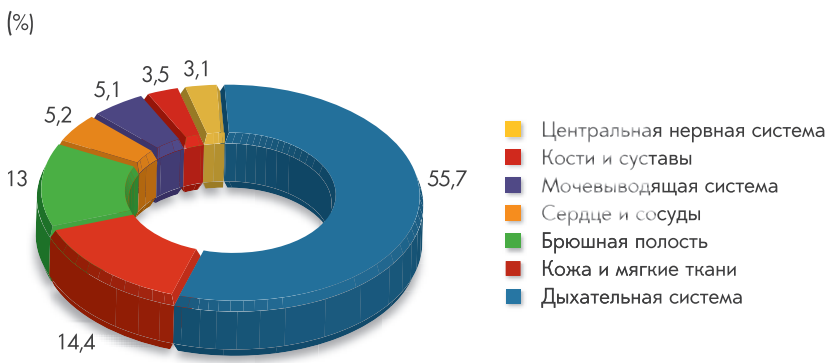

Рисунок 1. Распределение нозокомиальных изолятов Acinetobacter spp. (n = 1005) в зависимости от локализации инфекции

НИИ антимикробной химиотерапии (НИИАХ) ФГБОУ ВО СГМУ Минздрава России (Смоленск).

Видовая идентификация и хранение изолятов. Все исследованные изоляты были идентифицированы до вида методом матрично-ассоциированной лазерной десорбции/ионизации - времяпролетной масс-спектрометрии (MALDI-TOF MS) с использованием системы Microflex LT и программного обеспечения MALDI Biotyper Compass v.4.1.80 (Bruker Daltonics, Германия). В качестве критерия надежной видовой идентификации использовали рекомендуемые для представителей рода Acinetobacter значения Score $\geqslant 2,2$. Видовую идентификацию изолятов $A$. baumannii дополнительно подтверждали с помощью детекции генов видоспецифических бета-лактамаз группы ОХА-51 методом ПЦР в режиме реального времени с использованием коммерческих наборов «АмплиСенс® MDR Ab-OXA-FL» (ФБУН Центральный НИИ эпидемиологии Роспотребнадзора, Россия) и системы DTPrime 5X1 (ДНК-Технология, Россия). До проведения анализа изоляты хранили при температуре $-70^{\circ} \mathrm{C}$ в триптиказо-соевом бульоне с добавлением $30 \%$ глицерина.

Определение чувствительности к АМП. Определение чувствительности ко всем АМП проводили методом микроразведений в бульоне Мюллера Хинтон (Oxoid, Великобритания) в соответствии со стандартом ISO 20776-1:2006 / ГОСТ Р ИСО 207761-2010 [16,17]. Клинические категории чувствительности изолятов к АМП определяли на основании пограничных значений минимальных подавляющих концентраций (МПК), установленных Европейским комитетом по определению чувствительности к антимикробным препаратам (EUCAST), версия 9.0 [18], и российскими клиническими рекомендациями «Определение чувствительности микроорганизмов к антимикробным препаратам», версия 2018-03 [19]. Для контроля качества определения чувствительности использовали следующие штаммы: E. coli ATCC ${ }^{\circledR} 25922$, E. coli ATCC ${ }^{\circledR} 35218$ и P. aeruginosa ATCC ${ }^{\circledR 27853 . ~ А н а л и з ~ р е з у л ь т а т о в ~ о п р е д е л е н и я ~ ч у в с т в и-~}$ тельности к АМП проводился с помощью онлайн платформы AMRcloud (http://amrcloud.net/).

Выявление карбапенемаз. Наличие наиболее распространенных у Acinetobacter spp. генов приобретенных карбапенемаз класса D (групп ОХА-23, OXA-24/40, OXА-58 и OXА-143), а также карбапенемаз класса В (металло-бета-лактамаз (МБЛ) групп VIM, 
IMP и NDM) определяли методом ПЦР в режиме реального времени с использованием коммерческих на-

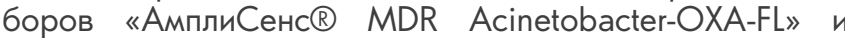

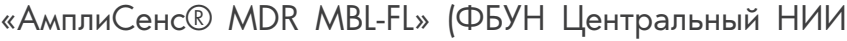
эпидемиологии Роспотребнадзора, Россия). Выявление и дифференциацию бета-лактамаз расширенного спектра (БЛРС) группы GES (GES-1-подобных БЛРС, содержащих аминокислотный остаток Gly170) и GES карбапенемаз (GES-2- и GES-5-групп, несущих замены Asn 170 и Ser170) проводили путем детекции соответствующих нуклеотидных полиморфизмов в позициях 493 и 494 генов bla геs $_{\text {с }}$ помощью метода ПЦР в реальном времени и анализа кривых плавления зонда [20]. Для амплификации использовали систему ПЦР в реальном времени DTPrime 5X1 (ДНК-Технология, Россия). В качестве положительных контролей использовались штаммы A. baumannii, A. pittii и P. aeruginosa, продуцирующие известные бета-лактамазы перечисленных групп, из коллекции НИИАХ. Результаты оценки чувствительности к АМП и определения генов карбапенемаз различных типов введены в онлайн базу данных AMRmap [21].

Молекулярно-генетическое типирование $\boldsymbol{A}$. baumannii. Для оценки генетического разнообразия штаммов A. baumannii применяли метод SNP-типирования, основанный на анализе однонуклеотидных полиморфизмов (SNP) в 10 хромосомных локусах (gltA, recA, cpn60, gyrB, gdhB, rpoD, fus $A$, pyrG, rp/B и rрoB), используемых в существующих схемах мультилокусного секвенирования-типирования (MLST) A. baumannii [22]. Метод обеспечивает возможность высокопроизводительного типирования изолятов и определения их принадлежности к известным сиквенс-типам (ST) и клональным комплексам (CC), включая так называемые «международные клоны высокого риска». Детекцию SNP в указанных локусах проводили с помощью аллель-специфичной ПЦР в режиме реального времени с универсальными флуорогенными праймерами (Amplifluor). Для подготовки и проведения ПЦР в формате 384-луночных планшет использовали систему QIAgility (QIAGEN, Германия) и DTPrime 5X1 (ДНК-Технология, Россия). В качестве контролей были использованы штаммы A. baumannii известных сиквенс-типов из коллекции НИИАХ. Кластерный анализ SNP профилей осуществляли с помощью онлайн ресурса SNPTAb (http://snpt.antibiotic.ru) [23] и программы PHYLOViZ 2 (http://www.phyloviz.net). Результаты типирования всех изолятов введены в онлайн базу данных SNPTAb.

\section{Результаты и обсуждение}

Результаты оценки чувствительности к АМП нозокомиальных изолятов Acinetobacter spp. представлены в Таблицах 2-4. Учитывая отсутствие критериев EUCAST для определения клинических категорий чувствительности Acinetobacter spp. к отдельным препаратам (пиперациллину/тазобактаму, цефтазидиму, цефепиму, сульбактаму и тигециклину), которые в ряде случаев используются для лечения инфекций, вызванных этим возбудителем, в соответствующих таблицах представлено только распределение МПК перечисленных антибиотиков. Большинство изолятов $A$. baumannii харак- теризовались высоким уровнем устойчивости in vitro $\mathrm{k}$ пиперациллину/тазобактаму, цефтазидиму и цефепиму соответствующие значения $М П K_{50 \%}$ и $М П K_{90 \%}$ для данных антибиотиков составили 128 - $\geqslant 256$ мг/л. Показатели МПК $50 \%$ и МПК $90 \%$ сульбактама составили 32 и 64 мг/л для A. baumannii и 1 и 32 мг/л для штаммов других видов Acinetobacter spp.; $М П K_{50 \%}$ и $М П K_{90 \%}$ тигециклина 1 и 4 мг/л для A. baumannii и 0,5 и 1 мг/л для штаммов других видов.

Резистентными к карбапенемам (имипенему и меропенему) были соответственно 77,4\% и 77,1\% изолятов A. baumannii. Крайне высокие показатели устойчивости отмечены для ципрофлоксацина $(99,0 \%)$. Частота резистентности к аминогликозидам (амикацину, гентамицину, нетилмицину и тобрамицину) составляла соответственно 89,2\%, 77,4\%, 64,2\% и 50,6\%. Устойчивость к ко-тримоксазолу выявлена у 41,2\% изолятов. Среди не-бета-лактамных антибиотиков наиболее высокой активностью in vitro обладал колистин (0,9\% резистентных изолятов). Значения $M П K_{50}$ и $М П К_{90}$ для тигециклина составили 1 и 4 мг/л соответственно (Таблица 2). Резистентными ко всем антибиотикам, за исключением колистина, были 20,5\% изолятов A. baumannii. Штаммы других видов Acinetobacter spp. характеризовались более высокой чувствительностью ко всем антибиотикам, за исключением колистина $(6,7 \%$ резистентных изолятов) (Таблица 3).

Наличие генов приобретенных карбапенемаз молекулярного класса D, относящихся к группам OXА-24/40 $(57,5 \%)$, OХA-23 $(18,4 \%)$ и ОХА-58 (0,1\%), выявлено у $743(76,2 \%)$ изолятов A. baumannii; причем у двух изолятов $(0,2 \%)$ - одновременное наличие генов ОХА-24/40- и ОХА-23-подобных бета-лактамаз. Генов МБЛ у изолятов A. baumannii обнаружено не было. Напротив, у других видов Acinetobacter spp. не было обнаружено генов приобретенных карбапенемаз класса $D$, однако у двух изолятов Acinetobacter ursingii и Acinetobacter baylyi, выделенных в разных стационарах Санкт-Петербурга, были выявлены гены МБЛ группы NDM. У всех исследованных изолятов Acinetobacter spp. не было найдено генов GES-5- и GES-2подобных карбапенемаз, однако гены БЛРС группы GES-1 были выявлены у 53 (5,4\%) изолятов A. baumannii из 7 городов (Москва, Мурманск, Пенза, Пермь, Петрозаводск, Ростов-на-Дону и Санкт-Петербург).

Результаты оценки чувствительности изолятов A. baumannii, несущих гены приобретенных ОХА-карбапенемаз, представлены в Таблице 4. Большинство продуцентов карбапенемаз характеризовались ассоциированной устойчивостью к аминогликозидам: от 57,3\% к тобрамицину до 91,7\% к амикацину. К триметоприму/ сульфаметоксазолу и колистину были резистентны 41,5\% и 1,1\% продуцентов карбапенемаз. Сравнение полученных данных с результатами прошлого периода исследования [14] свидетельствует о росте частоты устойчивости к карбапенемам и продукции карбапенемаз у нозокомиальных штаммов $A$. baumannii в России в основном за счет распространения ферментов группы OХА-24/40 (Рисунок 2).

Молекулярно-генетическое типирование позволило отнести все изоляты A. baumannii, выделенные в 20152016 гг., к 34 генотипам и 18 клональным группам 


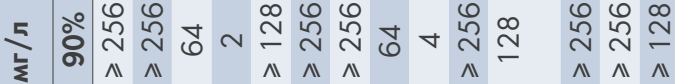
至

串

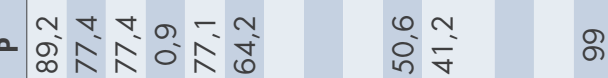

뜬 은

ำ

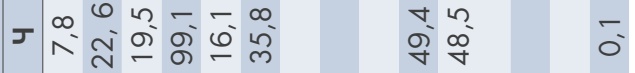

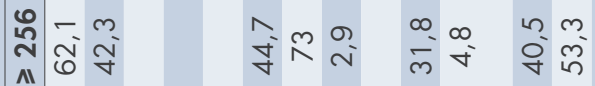

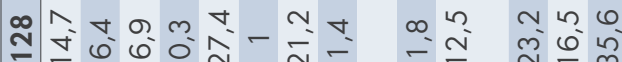

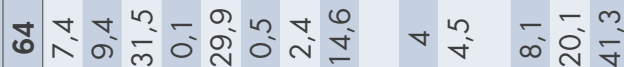

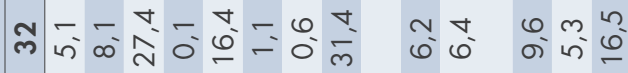

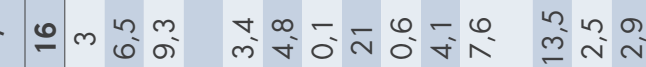

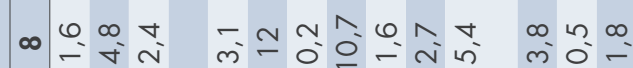

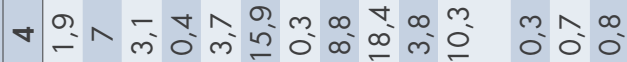

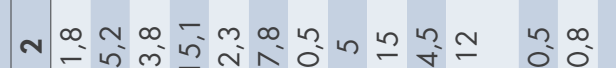

-

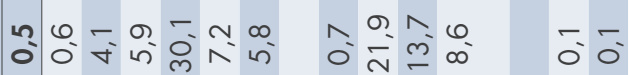

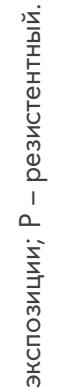

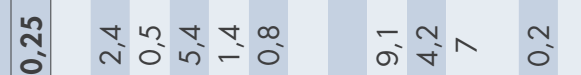

षं

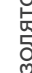

$\stackrel{m}{s}$

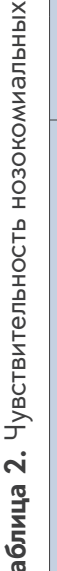

(1)

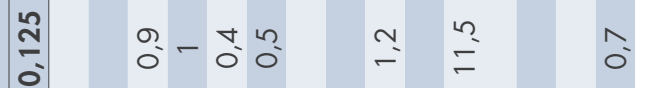

ind

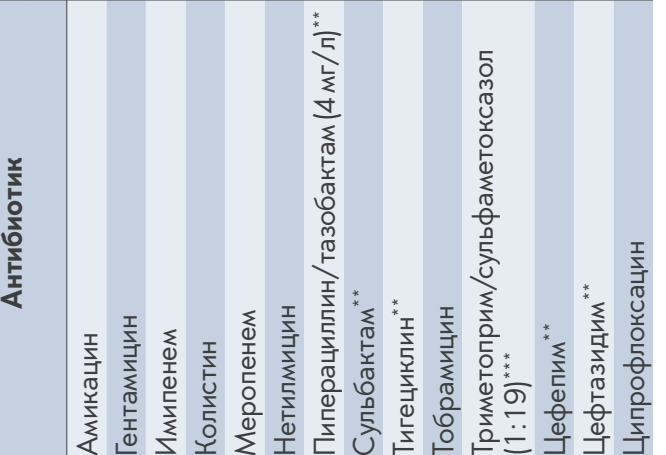

政

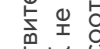

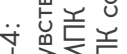

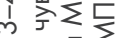

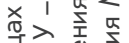

空空夏

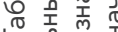

要这

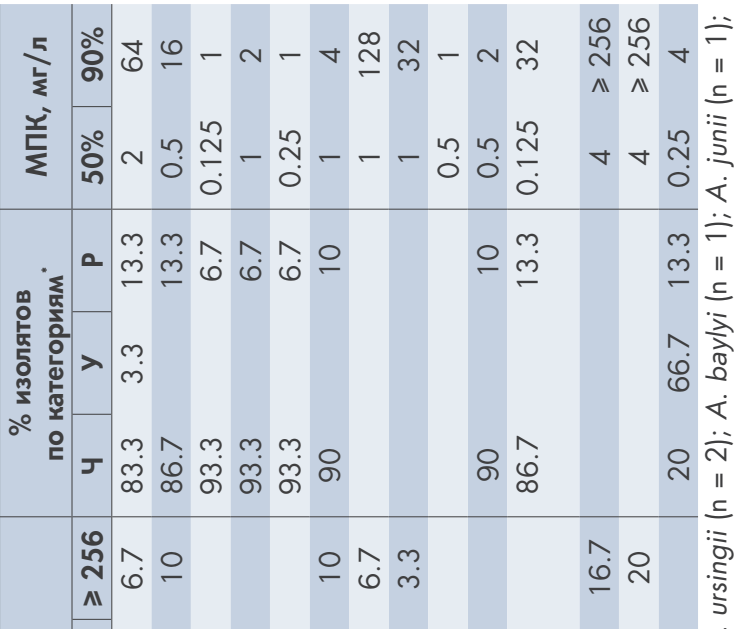

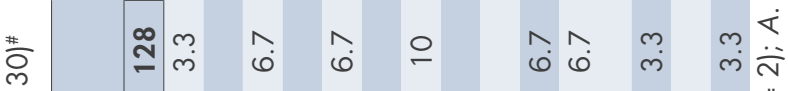

II

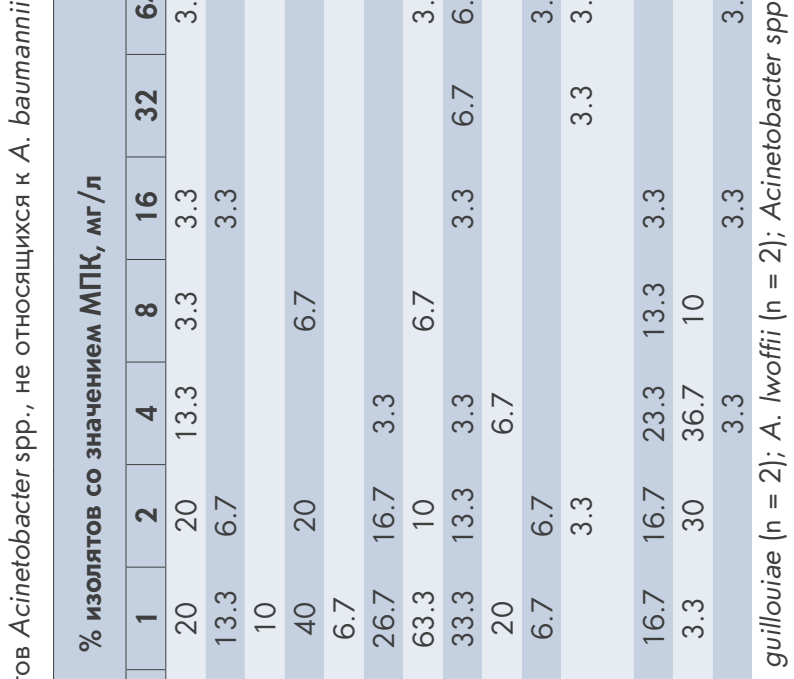

n

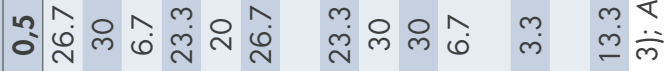

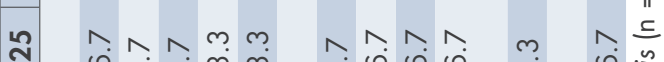
ㄱ.

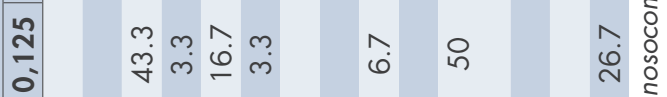

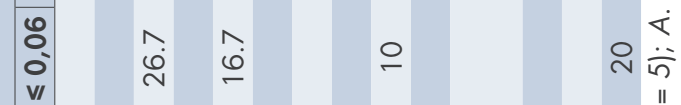

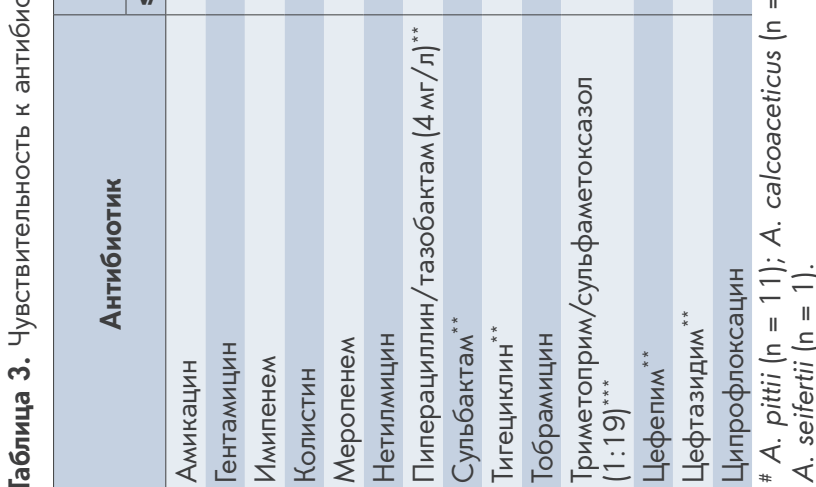




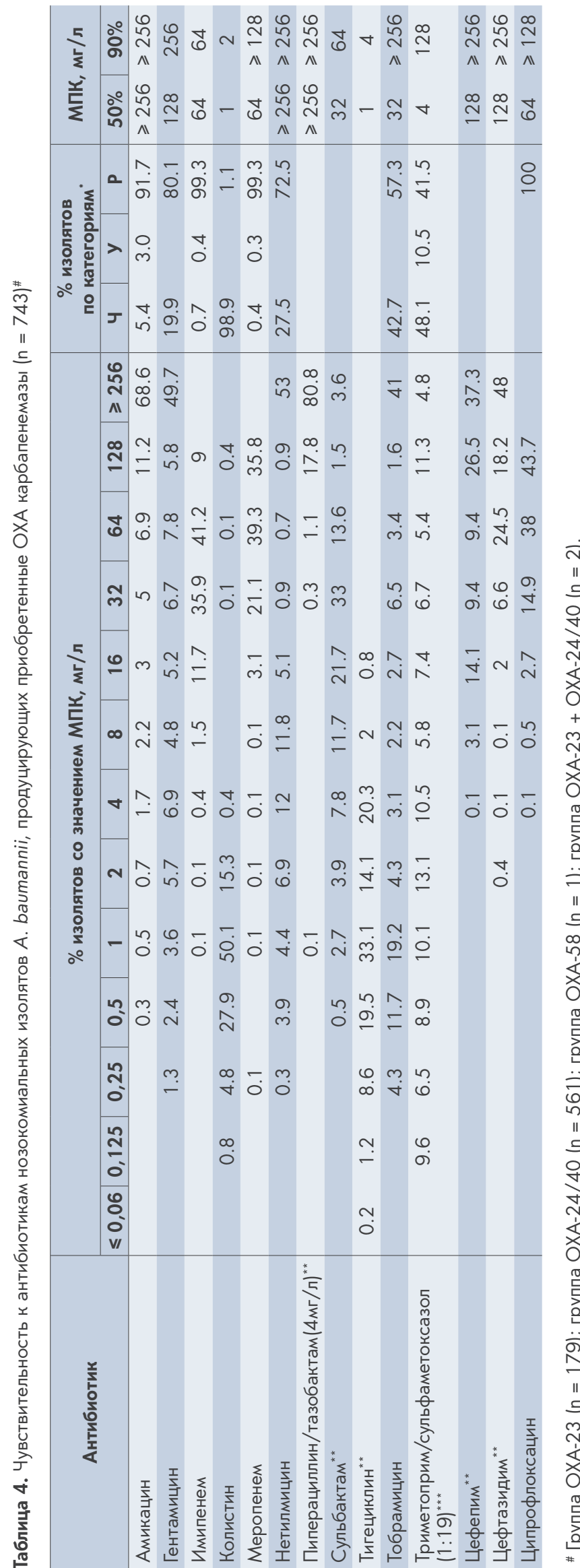

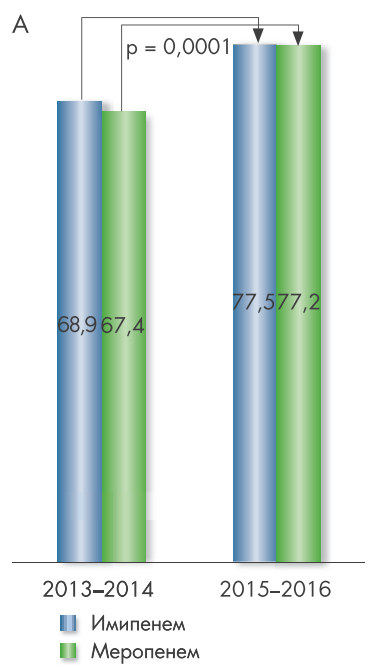

B

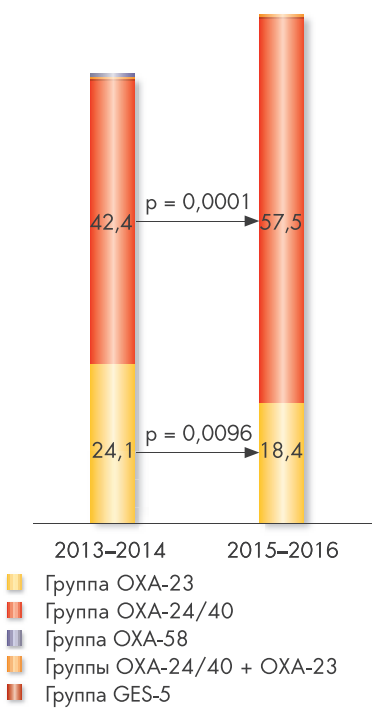

Рисунок 2. Динамика резистентности к карбапенемам (A) и продукции карбапенемаз (В) у нозокомиальных штаммов $A$. baumannii в России по данным исследований «МАРАФОН» в 2013-2014 гг. и 2015-2016 гг., \%

(генетическим кластерам, объединяющим штаммы родственных генотипов) (Рисунок 3). В стационарах 22 из 25 городов выявлено одновременное распространение множества различных клонов: наибольшее разнообразие - в Санкт-Петербурге (12 генотипов), Смоленске (11 генотипов), Пензе (10 генотипов), Москве и Ростовена-Дону (по 9 генотипов). Несмотря на очевидное разнообразие циркулирующих штаммов, отмечено преобладание штаммов трех генетических линий (клональных групп): CC92/208ОXF/CC2 ${ }^{\mathrm{PAS}}$ - международной клональной линии ICL2 (57,4\% изолятов, относящихся к 11 родственным генотипам, из 23 городов), СС944 XXF/CC78 PAS (19,6\% изолятов, относящихся к 2 родственным генотипам, из 21 города) и СС109/231 охғ $/ \mathrm{CC}^{\mathrm{PAS}}$ - международной клональной линии ICL1 (14,9\% изолятов, относящихся к 5 родственным генотипам, из 12 городов). CC944 OXF/CC78PAS представляет собой новый «международный клон высокого риска», распространение которого на территории России и нескольких европейских стран было описано ранее [12, 13, 24-26].

Доля устойчивых изолятов к карбапенемам (имипенему и меропенему) существенно различалась между тремя доминирующими клональными группами (CC944 OXF/CC78 $80,1 \%$, CC109/231 OXF $/ C C 1^{\text {PAS }}-59,3$ и 62,1\%) и была достоверно ниже у штаммов других генотипов $(39,7 \%$ и 30,8\%). При этом частота встречаемости приобретенных карбапенемаз была существенно выше у штаммов доминирующих клонов (СС944 ОXF $/$ CС $78^{\text {PAS }}-99,5 \%$, CC92/208 OXF/CC2 $2^{\text {PAS }}$ - 80,1\% и CC109/231 OXF/ CC $\left.1^{\text {PAS }}-59,3 \%\right)$ по сравнению со штаммами других генотипов $(21,8 \%)$. Гены приобретенных карбапенемаз были выявлены у изолятов, принадлежащих к 21 генотипу: гены ОХА-23-подобных карбапенемаз - у 10 генотипов, 
большинство из которых относились к генетической линии CC92/208 OXF/CC2 PAS; OXA-24/40-подобных карбапенемаз - у 14 генотипов всех трех основных клональных групп; гены ОХА-58-подобных карбапенемаз - у 1 штамма в составе CC109/231 OXF/CC1 PAs (Рисунок 3). Два изолята из Санкт-Петербурга и Казани, несущие одновременно гены двух различных карбапенемаз, были отнесены к одному генотипу - SNP-типу 16 (ST2080xF/ ST2 $2^{\text {PAS }}$. Интересно отметить, что карбапенемазы группы ОХА-24/40 были выявлены у 187 (99,5\%) из 188 изолятов CC944 OXF/CC78 PAS. В целом данная генетическая линия характеризовалась наиболее высокой частотой устойчивости к АМП разных групп. Резистентными ко всем препаратам, за исключением колистина, были $44,7 \%, 19,0 \%$ и 2,1\% изолятов, принадлежащих соответственно к СC944 OXF/CC78 ${ }^{\mathrm{PAS}}$, CC92/208 XXF/CC2 ${ }^{\mathrm{PAS}}$

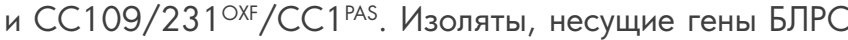
группы GES ( $n=53)$, были отнесены к 11 различным генотипам, большинство из них - к SNP-типу 35 (СC1100 OXF / CС500 1 PAS,$n=29)$ и SNP-типу 4 (СC109/231 OXF/CC1 PAS, $\mathrm{n}=8$ ). Устойчивость к колистину была выявлена у штаммов трех различных генотипов. Между штаммами раз- ных генотипов были выявлены значительные различия в устойчивости к отдельным не-бета-лактамным антибиотикам. Так, к тобрамицину были резистентны соответственно 94,2\% изолятов СС944\%ХF/CC78 PAs, 44\% изолятов $C C 92 / 208$ ОXF $/ C C 2^{\mathrm{PAS}}$ и лишь $14,5 \%$ изолятов CC109/2310XF/CC1PAS. Тобрамицин был активен in vitro в отношении 92,7\% и 95,2\% изолятов (включая продуцентов карбапенемаз), относящихся к двум основным генотипам, входящим в CC109/231 ХXF/CC 1 PAS: SNP-типу 4 (ST231/441/946 OXF/ST1 PAS) и SNP-типу 21 (ST441 OXF/ ST826 PAS), а также в отношении $87 \%$ изолятов наиболее распространенного генотипа в составе CC92/208 XхF CC2 ${ }^{\mathrm{PAS}}$ - SNP-типа 1 (ST2810XF/ST2 ${ }^{\mathrm{PAS}}$ ). Штаммы вышеперечисленных генотипов также были чувствительными к триметоприму/сульфаметоксазолу в 72,7\%, 71,4\% и $84,2 \%$ случаев соответственно. Таким образом, результаты проведенного исследования указывают на целесообразность рутинного определения чувствительности клинических штаммов $A$. baumannii к тобрамицину и триметоприму/сульфаметоксазолу и, в случае выявления чувствительности, использования данных АМП в составе комбинированной терапии.

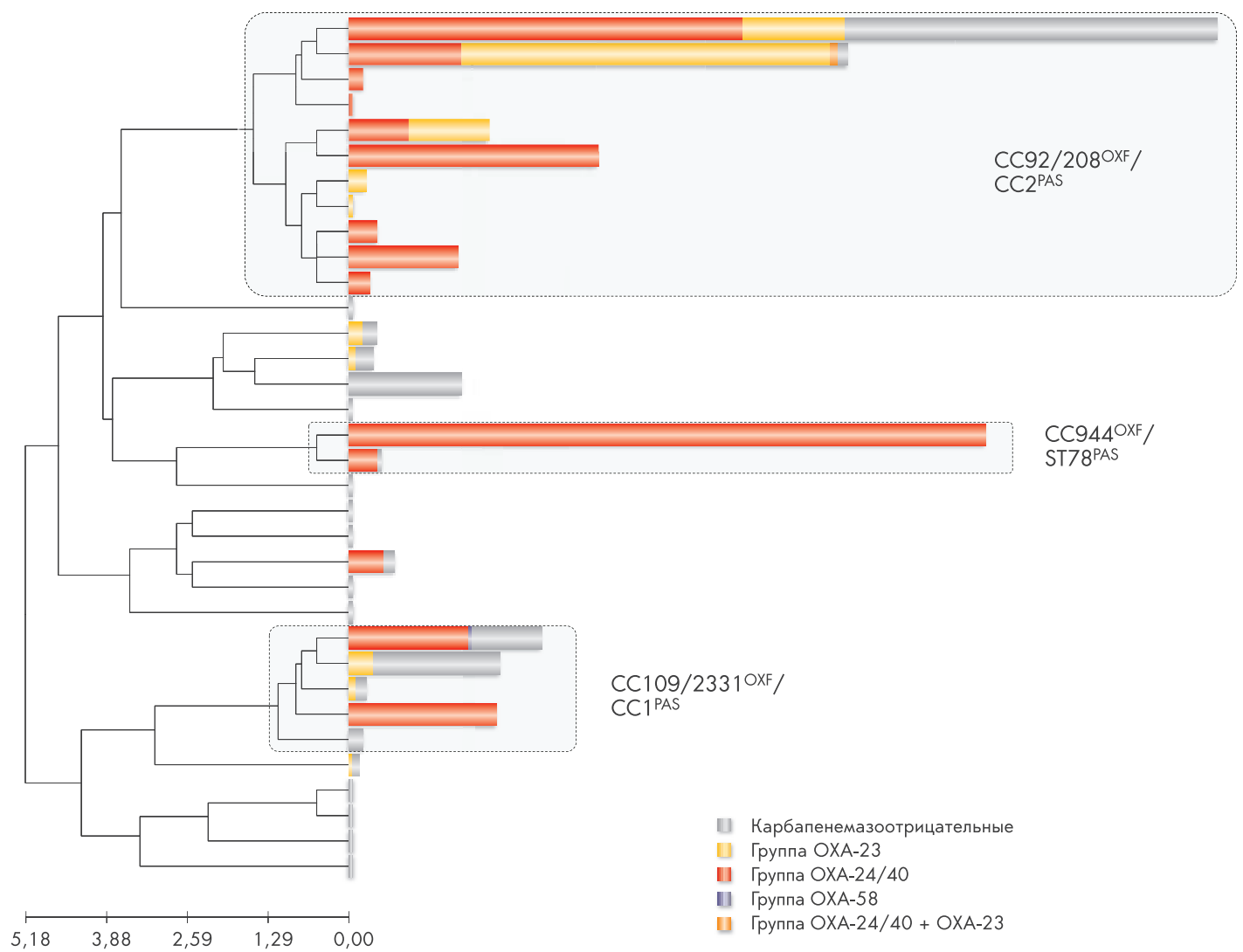

Рисунок 3. Генетическое разнообразие и продукция карбапенемаз у штаммов A. baumannii, выделенных в исследовании «МАРАФОН 2015-2016», по данным SNP типирования

Иерархический кластерный анализ SNP-профилей (метод полной связи). Горизонтальные прямоугольники соответствуют различным генотипам. Длина прямоугольников пропорциональна количеству изолятов. Доминирующие клональные группь выделены пунктирными линиями. 


\section{Заключение}

A. baumannii является одним из наиболее частых возбудителей нозокомиальных инфекций в России. Результаты исследования «МАРАФОН 2015-2016» свидетельствуют о чрезвычайно высокой распространенности резистентности к большинству антибиотиков, включая все бета-лактамы, применяемых для лечения вызванных данным возбудителем инфекций. Основным механизмом устойчивости $A$. baumannii к карбапенемам в настоящее время является продукция приобретенных карбапенемаз, относящихся к группе ОХА-24/40, и в меньшей степени ОХА-23. Карбапенемазы этих групп обнаруживаются у штаммов различных генотипов, однако большинство продуцентов карбапенемаз принадлежат к трем генетическим линиям, известным как «международные клоны высокого риска». Для штаммов СС944 ОXF/CC78 PAS, циркулирующих на территории России, характерна высокая частота устойчивости ко всем антибиотикам и продукция карбапенемаз группы

\section{Литература}

1. Kempf M., Rolain J.-M. Emergence of resistance to carbapenems in Acinetobacter baumannii in Europe: clinical impact and therapeutic options. Int J Antimicrob Agents. 2012;39(2):105114. DOI:10.1016/j.ijantimicag.2011.10.004

2. Dijkshoorn L., Nemec A., Seifert H. An increasing threat in hospitals: multidrug-resistant Acinetobacter baumannii. Nat Rev Microbiol. 2007;5(12):939-951. DOI:10.1038/nrmicro1789

3. Cosgaya C., Marí-Almirall M., Van Assche A., Fernández-Orth D., Mosqueda N., Telli M., et al. Acinetobacter dijkshoorniae sp. nov., a member of the Acinetobacter calcoaceticus-Acinetobacter baumannii complex mainly recovered from clinical samples in different countries. Int J Syst Evol Microbiol. 2016;66(10):41054111. DOI:10.1099/ijsem.0.001318

4. Nemec A., Krizova L., Maixnerova M., van der Reijden T.J.K., Deschaght P., Passet V., et al. Genotypic and phenotypic characterization of the Acinetobacter calcoaceticus-Acinetobacter baumannii complex with the proposal of Acinetobacter pittii sp. nov. (formerly Acinetobacter genomic species 3) and Acinetobacter nosocomialis sp. nov. (formerly Ac. Res Microbiol. 2011;162(4):393-404. DOI:10.1016/j.resmic.2011.02.006

5. Nemec A., Krizova L., Maixnerova M., Sedo O., Brisse S., Higgins P.G. Acinetobacter seifertii sp. nov., a member of the Acinetobacter calcoaceticus-Acinetobacter baumannii complex isolated from human clinical specimens. Int J Syst Evol Microbiol. 2015;65(Pt 3):934-942. DOI:10.1099/ijs.0.000043

6. Sedo O., Maixnerova M., Nemec A., Jezek P., Vrestiakova E., Radolfova-Krizova L. Taxonomy of haemolytic and/or proteolytic strains of the genus Acinetobacter with the proposal of Acinetobacter courvalinii sp. nov. Igenomic species 14 sensu Bouvet \&amp; Jeanjean), Acinetobacter dispersus sp. nov. (genomic species 17), Acinetobacter modestus sp. nov., Acinetobacter proteolyticus sp. nov. and Acinetobacter vivianii sp. nov. Int J Syst Evol Microbiol. 2016;66(4):1673-1685. DOI:10.1099/ijsem.0.000932

7. Nemec A., Radolfova-Krizova L., Maixnerova M., Sedo O. Acinetobacter colistiniresistens sp. nov. (formerly genomic species 13 sensu Bouvet and Jeanjean and genomic species 14 sensu Tjernberg and Ursing), isolated from human infections and characterized by intrinsic resistance to polymyxins. Int J
OXA-24/40. Штаммы CC92/2080XF/CC2 PAS (ICL2) и менее распространенные - CC109/2310XF/CC 1 PAS $(\mathrm{ICL} 1)$ продуцируют карбапенемазы различных типов и в ряде случаев чувствительны к отдельным не-бета-лактамным антибиотикам (тобрамицину и триметоприму/сульфаметоксазолу), в том числе при наличии устойчивости к карбапенемам. Резистентность к колистину встречается у единичных штаммов разных генотипов. Учитывая высокую вероятность устойчивости штаммов Acinetobacter spp. к основным АМП для лечения нозокомиальных инфекций, выбор антибиотиков для эмпирической терапии является крайне затруднительным и требует проведения регулярного локального мониторинга чувствительности в каждом стационаре.

Анализ детерминант резистентности и молекулярно-генетическое типирование штаммов A. baumannii выполнены при поддержке гранта Российского научного фонда (РНФ) №18-15-00403.
Syst Evol Microbiol. 2017;67(7):2134-2141. DOI:10.1099/ ijsem.0.001903

8. Martinovich A.A. Resistance Trends and Epidemiology of Acinetobacter Infections in Russia. Klinicheskaja mikrobiologija i antimikrobnaja himioterapija. 2012;14(2):96-105. Russian. (Мартинович А.А. Динамика антибиотикорезистентности и эпидемиология инфекций, вызванных Acinetobacter spp., в России. Клиническая микробиология и антимикробная химиотерапия. 2012;14(2):96-105.).

9. Reshedko G.K., Ryabkova E.L., Kretchikova O.I., Sukhorukova M.V., Shevchenko O.V., Edelstein M.V., Kozlov R.S., on behalf of ROSNET study group. Antimicrobial resistance patterns of gram-negative nosocomial pathogens in russia ICUs. Klinicheskaja mikrobiologija i antimikrobnaja himioterapija. 2008;10(2):96112. Russian. (Решедько Г.К., Рябкова Е.Л., Кречикова О.И., Сухорукова М.В., Шевченко О.В., Эйдельштейн М.В. и соавт. Резистентность к антибиотикам грамотрицательных возбудителей нозокомиальных инфекций в ОРИТ многопрофильных стационаров России. Клиническая микробиология и антимикробная химиотерапия. 2008;10(2):96-112.).

10. Reshedko G.K., Ryabkova E.L., Farashchuk A.N., Stratchounski L.S., and ROSNET study group. Non-fermenting gramnegative nosocomial pathogens in Russian ICUs: antimicrobial resistance problems. Klinicheskaja mikrobiologija i antimikrobnaja himioterapija. 2006;8(3):243-259. Russian. (Решедько Г.К., Рябкова Е.Л., Фаращук А.Н., Страчунский Л.С., Туркутюков В.Б., Нехаева Г.И. и соавт. Неферментирующие грамотрицательные возбудители нозокомиальных инфекций в ОРИТ России: проблемы антибиотикорезистентности. Клиническая микробиология и антимикробная химиотерапия. 2006;8(3):243-259.).

11. Skleenova E., Sukhorukova M., Timokhova A., Martinovich A., Savochkina J., Edelstein M., et al. Sharp increase in carbapenemnon-susceptibility and carbapenemase production rates in nosocomial Gram-negative bacteria in Russia over the last decade. Proceedings of the $53^{\text {rd }}$ Interscience Conference on Antimicrobial Agents and Chemotherapy (ICAAC). Denver, USA; 2012. C2-1092.

12. Giannouli M., Cuccurullo S., Crivaro V., Di Popolo A., Ber- 
nardo M., Tomasone F., et al. Molecular Epidemiology of Multidrug-Resistant Acinetobacter baumannii in a Tertiary Care Hospital in Naples, Italy, Shows the Emergence of a Novel Epidemic Clone. J Clin Microbiol. 2010;48(4):1223-1230. DOI:10.1128/JCM.02263-09

13. Sukhorukova M.V., Edelstein M.V., Skleenova E.Yu., Ivanchik N.V., Shek E.A., Dekhnich A.V., Kozlov R.S., and the "MARATHON" study group. Antimicrobial resistance of nosocomial Acinetobacter spp. isolates in Russia: results of multicenter epidemiological study "MARATHON" 2013-2014. Klinicheskaja mikrobiologija i antimikrobnaja himioterapija. 2017;19(1):42-48. Russian. (Сухорукова М.В., Эйдельштейн М.В., Склеенова Е.Ю., Иванчик Н.В., Шек Е.А., Дехнич А.В. и соавт. Антибиотикорезистентность нозокомиальных штаммов Acinetobacter spp. в стационарах России: результаты многоцентрового эпидемиологического исследования «МАРАФОН 2013-2014». Клиническая микробиология и антимикробная химиотерапия. 2017;19(1):42-48.).

14. Zarrilli R., Pournaras S., Giannouli M., Tsakris A. Global evolution of multidrug-resistant Acinetobacter baumannii clonal lineages. Int J Antimicrob Agents. 2013;41(1):11-19. DOI:10.1016/j. ijantimicag.2012.09.008

15. Karaiskos I., Giamarellou H. Multidrug-resistant and extensively drug-resistant Gram-negative pathogens: current and emerging therapeutic approaches. Expert Opin Pharmacother. 2014;15(10):1351-1370. DOI:10.1517/14656566.2014.9 14172

16. ISO 20776-1:2006 Clinical laboratory testing and in vitro diagnostic test systems - Susceptibility testing of infectious agents and evaluation of performance of antimicrobial susceptibility test devices - Part 1 : Reference method for testing the in vitro, 2006. Available at: www.iso.org/standard/41630.html. Accessed August 01, 2019.

17. National Standart GOST-R ISO 20776-1-2010. Clinical laboratory testing and in vitro diagnostic test systems. Susceptibility testing of infectious agents and evaluation of perfomance of antimicrobial susceptibility test devices, 2012. Available at: http://docs. cntd.ru/document/1200083430. Accessed August 01, 2019. Russian. (Национальный Стандарт ГОСТ Р ИСО 20776-1-2010 Клинические лабораторные исследования и диагностические тест-системы in vitro. Исследование чувствительности инфекционных агентов и оценка функциональных характеристик изделий для исследования чувствительности, 2012. Доступно по адресу: http://docs.cntd.ru/document/1200083430. Ссылка активна на 01 августа 2019 г.).

18. European Committee on Antimicrobial Susceptibility Testing (EUCAST). Breakpoint tables for interpretation of MICs and zone diameters. Ver. 9.0., 2019. Available at: http://www.eucast. org/clinical_breakpoints/. Accessed August 01, 2019.

19. Interregional Association for Clinical Microbiology and Antimicrobial Chemotherapy (IACMAC). Clinical guidelines. Susceptibility testing to antimicrobial agents. v. 2018-03. http:// www.antibiotic.ru/minzdrav/files/docs/clrec-dsma2018. pdf. Published 2018. Accessed August 1, 2019. Russian.
(Межрегиональная ассоциация по клинической микробиологии и антимикробной химиотерапии. Клинические рекомендации. Определение чувствительности микроорганизмов к антимикробным препаратам. Вер. 2018-03. http://www.antibiotic. $\mathrm{ru} / \mathrm{minzdrav} / \mathrm{files} /$ docs/clrec-dsma2018.pdf).

20. Sheck E.A., Skleenova E.Yu, Zhuravlev V.S, Edelstein M.V. Development of the assay for detection and discrimination of GES-type $\beta$-lactamases and assessment of their prevalence in gram-negative nosocomial pathogens in Russia. Proceedings of the Molecular Diagnostics 2017. Moscow, Russia; 18-20 April 2017. Р. 224-225. Russian. (Шек Е.А., Склеенова Е.Ю., Журавлев В.С., Эйдельштейн М.В. Разработка метода для детекции и дискриминации $\beta$-лактамаз GES-типа и оценка их распространения среди грамотрицательных возбудителей нозокомиальных инфекций в России. Сборник трудов IX Всероссийской научно-практической конференции с международным участием Молекулярная диагностика 2017. Москва, Россия; 18-20 апреля 2017. С. 224-225.).

21. Kuzmenkov A.Yu., Trushin I.V., Avramenko A.A., Edelstein M.V., Dekhnich A.V., Kozlov R.S. AMRmap: an online platform for monitoring antibiotic resistance. Klinicheskaja mikrobiologija i antimikrobnaja himioterapija. 2017;19(2):84-90. Russian. (Кузьменков А.Ю., Трушин И.В., Авраменко А.А., Эйдельштейн М.B., Дехнич А.В., Козлов Р.С. AMRmap: интернет-платформа мониторинга антибиотикорезистентности. Клиническая микробиология и антимикробная химиотерапия. 2017;19(2):84-90.).

22. Sheck E., Fedintsev A., Skleenova E., Martinovich A., Edelstein M. Development of a high-throughput single nucleotide polymorphism typing method for Acinetobacter baumannii (SNPTAb). Proceedings of the $25^{\text {th }}$ European Congress of Clinical Microbiology and Infectious Diseases (ECCMID). Copenhagen, Denmark; 25-28 April 2015. ePoster \#P0079.

23. Fedintsev A., Sheck E., Avramenko A., Trushin I., Edelstein M. Development of an online database and web application for analysis of SNP typing data of Acinetobacter baumannii. Proceedings of the $26^{\text {th }}$ European Congress of Clinical Microbiology and Infectious Diseases (ECCMID). Amsterdam, Netherlands; 9-12 April 2016. ePoster \#EP0313.

24. Giannouli M., Antunes L., Marchetti V., Triassi M., Visca P., Zarrilli R. Virulence-related traits of epidemic Acinetobacter baumannii strains belonging to the international clonal lineages I-III and to the emerging genotypes ST25 and ST78. BMC Infect Dis. 2013;13(1):282. DOl:10.1186/1471-2334-13-282

25. Munoz-Price L.S., Arheart K., Nordmann P., Boulanger A.E., Cleary T., Alvarez R., et al. Eighteen Years of Experience With Acinetobacter baumannii in a Tertiary Care Hospital. Crit Care Med. 2013;41(12):2733-2742. DOI:10.1097/ CCM.0b013e318298a541

26. Pfeifer Y., Hunfeld K.-P., Borgmann S., Maneg D., Blobner W., Werner G., et al. Carbapenem-resistant Acinetobacter baumannii ST78 with OXA-72 carbapenemase and ESBL gene blaCTX-M-115. J Antimicrob Chemother. 2016;71(5):14261428. DOI:10.1093/jac/dkv462 